\title{
Promoting Causal Agency The Self-Determined Learning Model of Instruction
}

\author{
MICHAEL L. WEHMEYER \\ SUSAN B. PALMER \\ Beach Center on Families and Disability University of Kansas \\ MARTIN AGRAN \\ University of Northern Iowa \\ DENNIS E. MITHAUG \\ Teachers College, Columbia University \\ JAMES E. MARTIN \\ University of Colorado at Colorado Springs
}

ABSTRACT: Teachers seeking to promote the self-determination of their students must enable them to become self-regulated problem-solvers. This article introduces a model of teaching, The Self-Determined Learning Model of Instruction, incorporating principles of self-determination, which enables teachers to teach students to become causal agents in their own lives. This model was field-tested with students with disabilities. Students receiving instruction from teachers using the model attained educationally relevant goals, showed enhanced self-determination, and communicated their satisfaction with the process. Teachers implementing the model likewise indicated their satisfaction with the process and suggested that they would continue to use the model after the completion of the field test.

Seymour Sarason (1990) suggested that an essential purpose of the educational process is to "produce responsible, self-sufficient citizens who possess the selfesteem, initiative, skills and wisdom to continue individual growth and pursue knowledge (p. 163). In many ways, this vision of education articulates the intent of initiatives to promote the self-determination of children and youth with disabilities. There is an emerging core of materials and methods to enable teachers to promote student self-determination (see Agran, 1997; Field, Martin, Miller, Ward, \& Wehmeyer, 1998; Wehmeyer, Agran, \& Hughes, 1998) and evidence that self-determination is, important for students to achieve positive adult outcomes (Wehmeyer \& Schwartz, 1997). These methods and materials focus on teaching: students to set goals, make decisions and choices, solve problems, self-advocate, and so forth. A critical element missing, however, in many 
however, in many efforts to "teach" self-determination is teaching students to take greater control over their own learning.

We have proposed that self-determined people are "causal agents" in their lives (Wehmeyer, 1996a, 1998; Wehmeyer, Agran, \& Hughes, 1998). They are actors in their lives instead of being acted upon; they make things happen in their lives. Consequently, a question of importance to educators is: How do we "teach" students to become causal agents in their lives? The answer, we suggest, lies in shifting from teacher-directed and teacher-driven instructional models to student-directed teaching models. Rather than continuing to rely upon instructional models in which the teacher is given full responsibility for determining when, what, why, where, and how a student will learn, there is a growing recognition that there may be marked advantages to having the student more actively involved in educational decision making, as well as the delivery of the instruction itself (Agran, 1997). Student-directed learning strategies place the responsibility for learning primarily with the student and involve the student in all aspects of his or her educational program.

Teaching students to take greater control over and responsibility for their own learning and to become causal agents in their lives is a process that often does not lend itself to traditional models of teaching. Joyce and Weil (1980) defined a model of teaching as "a plan or pattern that can be used to shape curriculums (long-term courses of study), to design instructional materials, and to guide instruction in the classroom and other settings" (p. 1). Such models are derived from theories about human behavior, learning, or cognition, and effective teachers employ multiple models of teaching, taking into account the unique characteristics of the learner and types of learning.

Like all educators, teachers working with students receiving special education services have an arsenal of teaching models they deploy according to a student's learning characteristics and the content under consideration. A teacher may use the role-playing model to teach social behaviors, social simulation, and social inquiry models to examine social problems and solutions, assertiveness training to teach self-advocacy skills, or a training model to teach vocational skills. Likewise, special educators employ more traditional, cognitively-based models of teaching, such as the concept attainment model to teach thinking skills, the memory model for increasing the retention of facts, or inductive thinking and inquiry training models to teach reasoning and academic skills. The teaching model most frequently adopted by special educators is the contingency management model drawing from principles contained in operant psychology.

The common theme across these models of teaching is that they are, by and large, teacher-directed. While these models provide direction for strategy and curriculum development activities that can teach components of self-determination, none adequately provides teachers direction to truly enable young people to become causal agents in their lives. We have proposed a model of teaching, called The Self-Determined Learning Model of Instruction (Mithaug, Wehmeyer, Agran, Martin, \& Palmer, 1998), derived from an earlier instructional model, the Adaptability Instruction Model proposed by several of the authors. The Self-Determined Learning Model of Instruction is based on the component elements of self-determination, the process of self-regulated problem-solving, and research on studentdirected learning. It is appropriate for students with and without disabilities across a wide range of content areas, and enables teachers to engage students in the totality of their educational programs by increasing opportunities to self-direct learning and, in the process, improve students' prospects for success after they leave school.

\section{MODELS OF INSTRUCTION}

\section{The Adaptability Instruction Model}

The Self-Determined Learning Model of Instruction was derived from the Adaptability Instruction Model forwarded by Mithaug, Martin, and Agran (1987) and Mithaug, Martin, Agran, and Rusch (1988). That model drew extensively from theory and research on self-control (Agran \& Martin, 1987; Bandura, 1986 
Kanfer \& Goldstein, 1986; Martin, Burger, Elias-Burger, \& Mithaug, 1988). Its purpose was to teach students with disabilities generic adaptability skills for use during school-to-work transitions. The authors suggested that by teaching decision making, independent performance, self-evaluation, and adjustment skills, students would improve their adjustments in postschool settings. The skills and the sequence of their use are as follows:

- Decision making: Students learn to identify their needs, interests, and abilities; consider alternatives; and then select their goals.

- Independent performance: Following goal selection, students learn independent performance by following through on their action plans. They perform tasks independently using self-management or student-directed learning strategies.

- Self-evaluation: While working on the tasks identified in their plans, students also learn to self-evaluate by monitoring and recording performance outcomes, then comparing their results with goals and performance expectations they set during decision making.

- Adjustments: In this phase, students learn to adjust their goal selection and behavior by connecting their future actions with past performance. Before beginning another task or project, they review feedback from previous decisions and performance outcomes and select goals, plans, and performance objectives accordingly.

\section{The Self-Determined Learning Model of Instruction}

Since publication of that model in 1987 , we have learned that the obstacles facing students with disabilities entering the mainstream of community life are more complex than we originally understood them to be. Through our separate work on selfdetermination (Agran, 1997; Agran \& Wehmeyer, 1999; Martin \& Marshall, 1996, 1998; Mithaug, 1996a, 1996b, 1998; Wehmeyer, 1996a, 1997, 1998; Wehmeyer, Agran, \& Hughes, 1998) we have concluded that students need to learn how to advocate for their own needs and interests by taking action to change circumstances that pose obstacles to their pursuits.
Simply adjusting to existing circum, stances does not accomplish this. The Self-Determined Learning Model of Instruction reflects this theoretical shift. It recognizes that success in life involves altering those circumstances to make, them more favorable for a self-selected pursuit. This is the essence of acting as a causal agent in one's life. The Self-Determined Learning Model of Instruction expands the intent of the Adaptability Model by identifying the skills that are necessary to act on the environment in order to achieve goals that satisfy one's self-defined needs and interests.

What the Adaptability Instruction Model failed to stress was that self-determined people persistently regulate their problem-solving to meet their own goals in life. The Self-Determined Learning Model of Instruction enables teachers to teach students to employ self-regulated problem-solving strategies to achieve self-selected goals using student-directed instructional strategies.

\section{Overview of The Self-Determined Learning Model of Instruction}

Implementation of the model consists of a three-phase instructional process depicted in Figures 1, 2, and 3. Each instructional phase presents a problem to be solved by the student. The student solves each problem by posing and answering a series of four student questions per phase that students learn, modify to make their own, and apply to reach self-selected goals. Each question is linked to a set of teacher objectives. Each instructional phase includes a list of educational supports identified that teachers can use to enable students to self-direct learning. In each instructional phase, the student is the primary agent for choices, decisions, and actions, even when eventual actions are teacher-directed.

The student questions in the model are constructed to direct the student through a problem-solving sequence in each instructional phase. The solutions to the problems in each'; phase lead to the problem-solving sequence in the next phase. Their construction was based on theory in the problem-solving and self-regulation literature that suggests that there is a sequence of thoughts and actions, a means-ends problem-solving 
FIGURE 1

Instructional Phase 1 for Self-Determined Learning Model of Instruction

Set a Goal
Problem for Student to Solve: What is my Goal?
Student Question 1: What do I want to learn?
Teacher Objectives
- Enable students to identify specific strengths and instructional needs.
- Enable students to communicate preferences, interests, beliefs, and values.
- Teach students to prioritize needs.
Student Question 2: What do I know about it now?
Teacher Objectives
- Enable students to identify their current status in relation to the instructional need.
- Assist students to gather information about opportunities and barriers in their environments.
Teacher Objectives
- Enable students to decide if action will be focused toward capacity building, modifying the environment, or both.
Student Question 4: What can I do to make this happen?
Teacher Objectives
- Teach students to state a goal and identify criteria for achieving goal.

Note: Educational supports include: (a) student self-assessment of interests, abilities, and instructional needs; (b) awareness training; (c) choice-making instruction; (d) problem-solving instruction; (e) decision-making instruction; and (f) goal-setting instruction.

a means-ends problem-solving sequence, that must be followed for any person's actions to produce results that satisfy their needs and interests. Teachers implementing the model teach students to solve a sequence of problems to construct a means-ends chain-a causal sequence-that moves them from where they are (an actual state of not having their needs and interests satisfied) to where they want to be (a goal state of having those needs and interests satisfied). Its function is to reduce or eliminate the discrepancy between what students want or need and what students currently have or know. We construct this means-ends sequence by having students answer the questions which connect their needs and interests to their actions and results via goals and plans.

To answer the questions in this sequence, students must regulate their own problem-solving by setting goals to meet needs, constructing plans to meet goals, and adjusting actions to complete plans. Thus, each instructional phase poses a problem the student must solve (What is my goal? What is my plan? What have I learned?) by, in turn, solving a series of problems posed by the questions in each phase. The four questions differ from phase to phase, but represent identical steps in the problem-solving sequence. That is, students answering the questions must: (a) identify the problem, (b) identify potential solutions to the problem, (c) identify barriers to solving the problem, and (d) identify consequences of each solution. These steps are the fundamental steps in any problemsolving process and they form the means-end problem-solving sequence represented by the student questions in each phase and enable the student to solve the problem posed in each instructional phase.

Because the model itself is designed for teachers to implement, the language of the student questions is, intentionally, not written to be understandable by every student, nor does the model assume that students have life experi- 
FIGURE 2

Instructional Phase 2 for Self-Determined Learning Model of instruction

Take Action
Problem for Student to Solve: What is my Plan?
Student Question 5: What can I do to learn what 1 don't know?
Teacher Objectives
- Enable student to self-evaluate current status and self-identified goal status.
Student Question 6: What could keep me from taking action?
Teacher Objectives
- Enable student to determine plan of action to bridge gap between self-evaluated
current status and self-identified goal status.
Student Question 7: What can I do to remove these barriers?
Teacher Objectives
- Collaborate with student to identify most appropriate instructional strategies.
- Teach student needed student-directed learning strategies.
- Pupport student to implement student-directed learning strategies.
- Erovide mutually agreed upon teacher-directed instruction.
Teacher Ouestion 8: When will I take action?

Note: Educational supports include: (a) self-scheduling; (b) self-instruction; (c) antecedent cue regulation; (d) choice-making instruction; (e) goal-attainment strategies; (f) problem-solving instruction; (g) decision-making instruction; (h) self-advocacy instruction; (i) assertiveness training; (j) communication skills training; and (k) self-monitoring.

ences that enable them to fully answer each question. The student questions are written in first-person voice in a relatively simple format with the intention that they are the starting point for discussion between the teacher and the student. Some students will learn and use all 12 questions as they are written. Other students will need to have the questions rephrased to be more understandable. Still other students, due to the intensity of their instructional needs, may need to have the teacher paraphrase the questions for them.

The first time a teacher uses the model with a student, the initial step in the implementation process is to read the question with or to the student, discuss what the question means and then, if necessary, change the wording to enable that student to better understand the intent of the question. Such wording changes must, however, be made such that the problem-solving intent of the question remains intact. For example, changing student question 1 from "What do I want to learn?" to "What is my goal?" changes the nature of the question. The teacher's objectives associated with each student question provide direction for possible wording changes. It is perhaps less important that actual changes in the words occur than that students take ownership over the process and adopt the question as their own, instead of having questions imposed on them. Going through this process once as the student progresses through the model should result in a set of questions that a student accepts as his or her own.

The teacher objectives within the model are just that-the objectives a teacher will be trying to accomplish by implementing the model. In each instructional phase, the objectives are linked directly to the student questions. These objectives can be met by utilizing strategies provided in the educational supports section of the model. The teacher objectives provide, in essence, a road map to assist the teacher to enable the student to solve the problem stated in the student question. For example, regarding the first student question: (What do I want to learn?), teacher objectives linked to this question comprise the activities in which students should be engaged in order to answer this question. In this case, it involves enabling students to, identify their specific strengths and instructional needs; to identify and communi- 


\section{FIGURE 3}

Instructional Phase 3 for Self-Determined Learning Model of Instruction

Adjust Goal or Plan
Problem for Student to Solve: What have I Learned?
Student Question 9: What actoins have I taken?
Teacher Objectives
- Enable student to self-evaluate progress toward goal achievement.
Student Question 10: What barriers have been removed?
Teacher Objectives
- Collaborate with student to compare progress with desired outcomes.
Student Question 11: What has changed about what I don't know?
Teacher Objectives
- Support student to reevaluate goal if progress is insufficient.
- Assist student to decide if goal remains the same or changes.
- Collaborate with student to identify if action plan is adequate or inadequate
given revised or retained goal.
Student Question 12: Do I know what I want to know?
Teacher Objectives
- Enable student to decide if progress is adequate, inadequate, or if goal has been achieved.

Note: Educational supports include: (a) self-evaluation strategies; (b) choice-making instruction; (c) problem-solving instruction; (d) decision-making instruction; (e) goal-setting instruction; $(f)$ self-reinforcement strategies; (g) self-monitoring strategies; and $(h)$ selfrecording strategies.

cate preferences, interests, beliefs and values; and to prioritize their instructional needs. As teachers use the model it is likely that they can generate more objectives that are relevant to the question, and they are encouraged to do so.

The educational supports are not actually a part of the model, per se, but are what Joyce and Weil (1980) refer to as the model's syntax- how the model is implemented. However, because the implementation of this model requires teachers to teach students to self-direct learning, we believe it is important to identify some strategies and supports that could be used to successfully implement the model. The majority of these supports are derived from the self-management literature. As previously indicated, student-directed learning strategies involve teaching students to modify and regulate their own behavior. A variety of strategies, like permanent prompts (antecedent cue regulation), self-instruction, self-monitoring, self-evaluation, self-reinforcement, and goal setting, have been used to teach students, including students with significant disabilities, how to manage their own behavior.

The emphasis in the model on the use of instructional strategies and educational supports that are student-directed provides another means of teaching students to teach themselves. As we have already indicated, teaching students to use the student questions will teach them a self-regulated problem-solving strategy. Concurrently, teaching students to use various student-directed learning strategies provides students with another layer of skills that enable them to become the causal agent in their lives.

As important as it is to utilize the student-directed learning strategies, not every instructional strategy implemented will be student-directed. The purpose of any model of teaching is to promote student learning and growth. There are circumstances in which the most effective instructional method or strategy to achieve a particular educational outcome will be a teacher-directed strategy. One misinterpreta 
tion of self-determination is that it is synonymous with independent performance. That is, people misinterpret self-determination as meaning that you do everything yourself. However, causal agents do not necessarily do everything for themselves, but instead are the catalysts in making things happen in their lives. Students who are considering what plan of action to implement to achieve a self-selected goal can-in fact should-recognize that teachers have expertise in instructional strategies and take full advantage of that expertise. For example, a student may identify learning to drive as an instructional need, and identify his reading level as one barrier to achieving that end. Together with his teacher, that student may decide that direct instruction in word attack skills is the best way to achieve the literacy level he needs to take the driver's test. The student remains the causal agent in this process, even if he or she is not using a student-directed learning strategy.

We have developed guides in the use of the model for teachers working with adolescents (Wehmeyer, Agran, Palmer, Mithaug, \& Blanchard, 1998) and with children in early elementary school (Palmer \& Wehmeyer, 1998), and readers are referred to these guides for more detail on model implementation. The remainder of this article reports findings from the field test of the model. This field test was implemented to examine two aspects of the efficacy of the model. First, the intent of any model of instruction is to support teachers to teach students educationally relevant skills or knowledge. Thus, the first level of evaluation of any instructional model is to show that when teachers use the model, students achieve educationally valuable goals. We have also hypothesized that in addition to teaching educationally relevant goals, this model will have a secondary effect of promoting student self-determination. The field test of the model evaluated both aspects of the efficacy of the model.

\section{METHOD}

\section{Participants}

To conduct a field test of The Self-Determined Learning Model of Instruction, we recruited 21 teachers responsible for the instruction of adolescents receiving special education services in two states (Texas and Wisconsin). Each teacher was asked to identify at least one but no more than three students with whom to implement the model. Teachers were nominated for participation in the project by district administrators, who were asked to recommend experienced teachers who would have the capacity to implement the model effectively.

Teachers worked collaboratively with project staff to identify students for involvement in the project. A total of 40 students ( 34 from Texas, 6 from Wisconsin) eventually received instruction from teachers using the model. Thirteen of the students were identified as having mental retardation $(\mathrm{M}$ age $=$ 17.23, M IQ = 55), 17 students had a learning disability (M age $=15.35$, M IQ $=88.29$ ), and 10 students were identified as having an emotional or behavioral disorder $(\mathrm{M}$ age $=14.2 \mathrm{M}$ $\mathrm{IQ}=97.9$ ). Concurrently, project staff in both states provided intensive training to teachers on self-determination, student-directed learning, and the model itself. Teachers were provided with several resources (textbooks, journal articles) that provided detailed information on using the various educational supports and were provided ongoing technical assistance from project staff to enable them to fully implement the model.

Once student selection was complete, teachers met with the students to explain the intent of the instructional process. Informed consent was obtained for all students involved in the field test. Teachers then began using the model to teach students. Since the model incorporates a student-directed goal selection process, there was no attempt to identify which educational goals might be addressed using the model, and a wide array of goals was selected for instruction. Students identified a total of 43 goals to be addressed using the model, and three students received instruction using the model on two goals. Of the 43 goals, 10 focused on acquiring or modifying social skills or knowledge, 13 focused on behavioral issues (compliance with school procedures, controlling behavior in specific circumstances, learning more adaptive behavior) and 20 addressed academic needs. 


\section{Measurement}

As was previously suggested, our evaluation focused on the efficacy of the model to enable teachers to teach students educationally valuable skills and knowledge and to promote selfdetermination. To achieve the first objective, we used the goal attainment scaling (GAS) process. The GAS has been used to measure goal attainment and to determine program effectiveness (Kiresuk, Smith, \& Cardillo, 1994) and has been extended to special education (Carr, 1979). According to Carr, GAS "basically involves establishing goals and specifying $a$ range of outcomes or behaviors that would indicate progress toward achieving those goals" (p. 89). The GAS scores were determined by the following procedures.

Once students identified a goal, working through the first phase of the model, the teacher met with a project staff member to identify five possible goal outcomes for each goal using a 5 point continuum ranging from the most unfavorable possible outcome to the most favorable possible outcome. Such goal outcomes are individually determined and can be described in quantifiable (e.g., percentage of correct attempts) or in less quantified (arrives to school with hair combed) terms. Each point on the 5point scale is assigned a value, beginning with -2 for the least favorable outcome, -1 for the less (not least) favorable outcome, 0 points for acceptable outcomes, +1 for favorable outcomes, and +2 for the most favorable outcome.

At the end of the instructional period (e.g., after students had received instruction using the model), teachers selected the outcome that best described the student's progress on the goal. Using a raw-score conversion key for GAS developed by Cardillo (1994), raw scores were converted to standardized T-scores (Kiresuk, Smith, \& Cardillo, 1994) with a mean of 50 and a standard deviation of 10 . The transformation of the raw scores to a standardized score allows comparison between goal areas across subjects independent of the particular goal area. When interpreting scores from the GAS, it is important to note that the converted mean T-score value of 50 represents an acceptable outcome, where an "acceptable" outcome means that students learned the goal or skills to the level expected by the teacher. Standardized scores of 40 or below indicate that the student did not achieve an acceptable outcome, and scores of 60 and above indicate that the student's progress exceeded expectations. The GAS scores for students who worked on more than one goal were calculated by averaging the standardized scores from the two goals.

The second area of measurement involved determining the degree to which instruction using the model enhanced student self-determination. We used three measures to evaluate this, and all students completed these measures prior to and after instruction. The first was The Arc's Self-Determination Scale (Wehmeyer \& Kelchner, 1995), a self-report measure of selfdetermination. This is a 72 -item scale that provides data on each of four essential characteristics of self-determination proposed by Wehmeyer (1996a, 1998) as well as overall self-determination. Section 1 measures student autonomy, including the student's independence and the degree to which he or she acts on the basis of personal be-liefs, values, interests, and abilities. Higher scores on this section reflect increased autonomy. The second section measures student self-regulation, specifically in two subdomains: interpersonal cognitive problem-solving, and goal-setting and task performance. Higher scores reflect effective social problem-solving and goaloriented behaviors.

The third section of the scale is an indicator of psychological empowerment. Students choose from items measuring psychological empowerment using a forced-choice method. High scores reflect positive perceptions of control. The final section of The Arc's Self-Determination Scale measures student self-realization, including self awareness and selfknowledge. High scores reflect high levels of self-realization.

The Arc's Self-Determination Scale was normed with 500 students with and without cognitive disabilities in rural, urban, and suburban school districts in five states. The scale's concurrent criterion-related validity was established by showing relationships between The Arc's Self-Determination Scale and conceptually related measures. The scale had adequate construct validity, including factorial validity estab- 
lished by repeated factor analyses, and discriminative validity The scale had adequate internal consistency $((\mathrm{x}=90)$ (Wehmeyer, 1996b). The scale has been used in several research efforts with students with disabilities (Sands, Spencer, Gliner, \& Swaim, 1999; Zhang, 1998), including our own work in which it was used to group students with disabilities leaving high school according to relative self-determination status. This study found that grouping students based on scores from The Arc's Self-Determination Scale predicted better adult outcomes 1 year later (Wehmeyer \& Schwartz, 1997).

In addition to measuring global self-determination, we were interested in measuring the degree to which students' perceptions of control in their lives changed as a result of instruction using the model. Each student completed, again both preand postinstruction, the Adult Version of the NowickiStrickland Internal-External Scale (ANS-IE; Nowicki \& Duke, 1974). The ANS-IE consists of 40 items answered with a "yes" or "no" and higher scores reflect more external orientations. The scale has reported split-half reliability figures ranging from .74 to .86 , with Test-Retest Reliability figures ranging from .63 to .76 . Although normed with adults without disabilities, the instrument has been used to determine locus of control orientation for adolescents and adults with cognitive disabilities (Wehmeyer, 1993a, 1994). Wehmeyer (1993b) determined that the factor structure of the ANSIE, when used with individuals with mental retardation, was comparable to that for youth and adults without disabilities and that the scale was reliable for use with individuals with mental retardation.

The last student indicator used was a questionnaire examining student goal orientation. This questionnaire was adapted from the American Institutes for Research (AIR) SelfDetermination Scale (Wolman, Campeau, Dubois, Mithaug, \& Stolarski, 1994). We selected six questions from the AIR scale related to goal-oriented behavior to which students responded "yes" or "no." These questions are listed in Figure 4. Although there has been no evaluation of the psychometric properties of this questionnaire, responses were summarized only on an itemby-item basis (described as follows) and there was no attempt to compute a total score, or indeed any score, from this process.
Because there are a number of teacher-related variables which might impact the efficacy of the model, we also collected information from 12 teachers in Texas regarding their prior use of student-directed learning strategies, the utility of the technical supports provided, and their perceptions of the utility of the model.

Analysis

Student GAS scores were calculated and results, including the mean total score, were presented graphically. Analysis of variance by disability label was conducted on GAS scores to examine differences in model efficacy by disability category and by type of goal (academic, social, or behavioral). Scores from The Arc's Self-Determination Scale and the ANS-IE were analyzed using a paired-samples T-test. Responses to the goals questionnaire were presented graphically.

\section{RESULTS}

Analysis of variance indicated no significant differences on GAS scores between students grouped by disability label or by type of goal. The mean GAS score for the total sample was 49.13 ( $\mathrm{SD}=14.063)$. Results showed that $25 \%$ of the standardized GAS scores equaled 50 , while $30 \%$ of the scores were higher than 50 , indicating that teachers rated $25 \%$ of the total number of goals on which students received instruction as having been achieved as expected and rated progress on $30 \%$ of the total goals as having exceeded expectations. Of the remainder, slightly more than $25 \%$ of the GAS scores were between 40 and 49 , indicating that students made progress on their goal, but did not fully achieve it, and just under $20 \%$ were rated as the least favorable outcome, essentially indicating no progress on the goal.

Paired-sample T-tests examining pre- and postintervention differences on self-determination and perceptions of control indicated significant differences on both The Arc's Self-Determination Scale $(p=.046)$ and the NowickiStrickland locus of control scale $(\mathrm{p}=.029)$. 


\section{FIGURE 4}

Questions Comprising the Goals Questionnaire
Questions
Do you have any interests right now?
Do you have any goals right now?
Do you have any plans for meeting the goal you mentioned?
Do you know when you will meet your goal?
Have you thought about whether your plans are working or not?
Do you have ways at school to reach your goal?

In both cases, mean scores were more adaptive after instruction. The mean score on The Arc's Self-Determination Scale prior to instruction was 94, with the mean score of 99 after instruction. The mean score on the locus of control scale prior to instruction was 15.8, after instruction it was 14.1 (lower scores are more adaptive). Figure 5 presents the percentage of "yes responses to each question on the goals questionnaire before and after instruction. Responses to teachers interviewed after they had implemented the model are provided in Table 1.

\section{DISCUSSION}

The findings from the field test support the potential utility of The Self-Determined Learning Model of Instruction to assist teachers to enable students with disabilities to selfregulate learning and to enhance self-determination. The mean score for the GAS process was 49.13, showing that on the average students receiving instruction using the model attained the educationally relevant goals at the level expected by the teacher. More than $30 \%$ of the teacher's ratings of student progress indicated that students had exceeded expectations in their goal achievement. Overall, slightly over $80 \%$ of students made at least some progress toward their goal receiving instruction using the model, and 55\% achieved their goal or exceeded it.

Even the fact that $45 \%$ of the goals fell short of the "acceptable" level does not lead to the conclusion that the model was ineffective or only slightly effective. Because of the time limitations imposed by the project-driven field test, we asked that students work completely through the model once. However, the model itself is set up to encourage adjustment to sev eral aspects of the process. We recognize that students with disabilities often have limited experience with self-regulation, goalsetting, and problem-solving. Given that the first phase of the model enables teachers to support students to identify personally valued instructional goals, it is more than likely that many students will not select the right goal the first time through the model. Likewise, students may not identify a fully effective action plan the first time through the model. That is why the third phase of the model encourages students to selfevaluate their progress toward achieving their goal and, if they determine that progress is inadequate, to evaluate whether the lack of progress was due to an inappropriate goal, an ineffective action plan, or simply failure to implement their current plan for a sufficient amount of time. As such, a certain amount of "failure" might actually be expected as the student works through the model the first time. Under circumstances that did not have the artificial time limitations of a field test, students would either revise their goal, change their action plan, or keep working on the goal.

That said, there are several factors that could impact the model's efficacy. First, teachers apply different models based on the characteristics of the student and the content area, but also on their own preferences and theoretical perspectives. Not every model is a fit with every teacher. We believe that The Self-Determined Learning Model of Instruction will be a good fit with many teachers, but hardly expect all teachers to embrace it. However, teachers using the model who responded to the questions were favorable in their responses to the model's potential benefit and its utility. Ten of the 12 teachers indicated that students involved in instruction using the model spontaneously approached them (the teachers) to discuss 


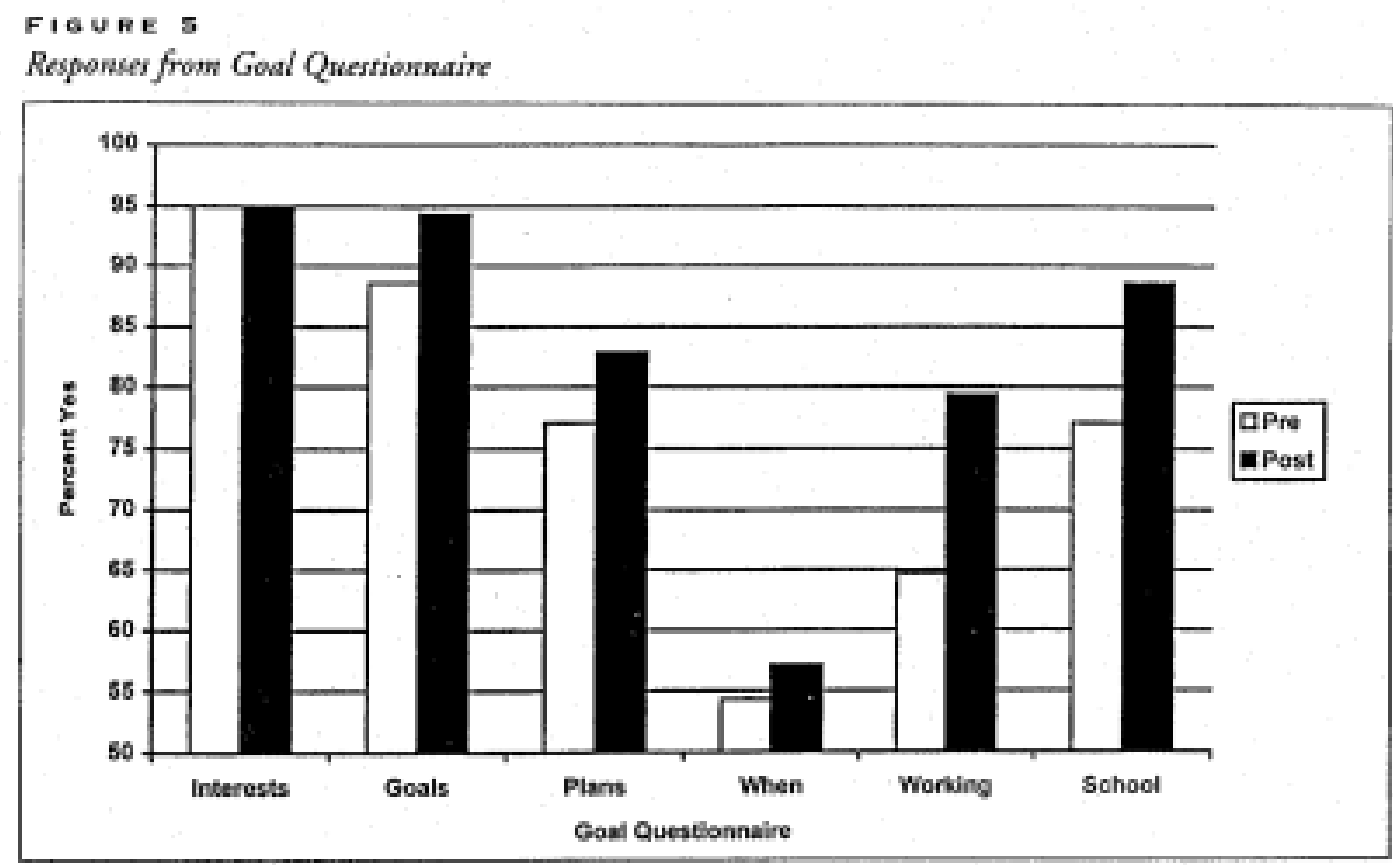

TABLE I

Frequency of Responses from Teachers Who Used the Model

\begin{tabular}{lll}
\hline Teacher Questions & $Y e s$ & $N o$ \\
\hline Have you ever used a self-management strategy in your classroom? & 3 & 9 \\
Have you received training to use self-management strategies? & 3 & 9 \\
Do students in your school attend IEP meetings? & 9 & 3 \\
$\begin{array}{l}\text { Once students were involved in instruction, did they come } \\
\text { to you (unsolicited) to talk about their progress? }\end{array}$ & 10 & 2 \\
$\begin{array}{l}\text { Will you continue to use the model next year? } \\
\begin{array}{l}\text { Did you gain new teaching skills/knowledge as a result of } \\
\text { implementing the model? }\end{array}\end{array}$ & 12 & 0
\end{tabular}

progress on their goals. Eleven of the 12 indicated they gained new knowledge or skills as a result of implementing the model, and all 12 indicated they would continue to use the model after the field test ended.

A second factor influencing efficacy involves teacher familiarity with and training in the use of self-management and student-directed learning strategies. Only three of the 12 teachers surveyed indicated that they had previous train- ing in using self-management strategies. Just as students will become more efficient self-regulated problem-solvers as they use and reuse the process, so too will teachers become more effective with the model as they become better able to teach self-management strategies like problem-solving or goal-setting. The current study does not provide evidence one way or the other as to the influence of these and other teacher variables on model efficacy, nor does it provide information about 
student and content-related factors that might influence efficacy, although such research would be beneficial and should be part of the future evaluation of the model.

In addition to suggesting that the model is educationally valid and effective, the field test also provided evidence that students receiving instruction became more self-determined. Students showed postintervention gains in self-determination scores and had more adaptive perceptions of control. As Figure 5 showed, students completing the goals questionnaire showed a consistent trend toward increased goal setting and attainment capacity. There are many aspects of the model that could have putative benefit to student self-determination. At the most obvious level, students learn effective problem-solving and goal-setting skills. Additionally, students become more aware of their interests, preferences, skills, and limitations. They must become more effective decision makers, selecting from a variety of options. They learn to self-regulate their behavior, to implement actions to achieve goals, and to evaluate and revise such actions as needed. As a function of their analysis of the environments in which they learn, live, or work, they will need to acquire self-advocacy, assertiveness, and leadership skills if they are to remove barriers that prohibit them from achieving self-selected goals. The model provides a means of getting students actively involved in the totality of their educational program and, presumably, will promote a greater commitment to that program by the student.

This field test also suggested that the model has utility across a variety of disability categories. There were no significant differences in GAS scores by disability label. We believe that the flexibility of the model process, both in enabling teachers to work with students to reword questions and the use of a wide array of educational supports makes the model appropriate for students with and without disabilities and, indeed, across a wide age range as well. We are currently implementing the model with students with disabilities in the early elementary years (Palmer \& Wehmeyer, 1998) and with transition age youth with significant disabilities (Agran, Blanchard, $\&$ Wehmeyer, in press). That said, a slightly higher percentage of students with mental retardation had GAS standardized scores of 40 or below than did either students with learning disabilities or emotional disorders. This probably indicates the need for students with mental retardation to have more time to work through the process, including revising goals and action plans as necessary. Despite this, almost $60 \%$ of students with mental retardation achieved or exceeded their goals, providing evidence that many students with mental retardation will benefit from this instruction.

Another benefit of the model is that students expressed their interest in and satisfaction with the model and its outcomes. Many students indicated that they liked setting their own goals and would continue to do so. One student said that she "learned how to make choices and decisions about how to control myself" and concluded that "it felt good and it will help me later on." A 14-year-old student indicated that he "learned about myself, that I could do anything if I tried." A 16year-old with mental retardation stated, "This was one of the few times I have been able to make some decisions about what I want to learn to do at school. I'm proud of what I did this year, and next year I want to do as well." Teachers indicated similar support for the model, suggesting that it provided a useful way to get students to set goals. One teacher also noted that she learned that "students are very capable of setting their own goals and achieving them. The goals mean a lot more when they set them themselves."

Finally, the model seems to have applicability across a wide range of educational content areas as well, as there were no significant differences in GAS scores based on goal type. Again, future research will need to examine what content areas might be best approached using the model, and the model is clearly not the best approach for teaching all subjects. Nonetheless, the model has the appeal of addressing a wide number of educational content areas and, in so doing, enables students to become more self-determined and, ultimately, causal agents in their lives.

\section{IMPLICATIONS FOR PRACTICE}

Promoting student self-determination is a complex process that will require a variety of educational activities across the student's educational experience. Such efforts will include active student 
involvement in educational planning and decision making, targeted instruction in component elements of self-determination (problem-solving, goal setting, decision making, etc.), and opportunities to express preferences, make choices, and learn about individual strengths and limitations. Educators need a variety of supports to enable them to succeed in this endeavor, from access to curricular and assessment materials and training, to administrative support, and there are more such supports available for use in the classroom (see Field et al., 1998; Wehmeyer, Agran, \& Hughes, 1998, for practice-based suggestions for promoting self-determination). The Self-Determined Learning Model of Instruction was developed to provide an additional piece of that process, a teaching model that provides a process by which teachers can promote self-regulated problem-solving and enhance self-determination.

The model is, in and of itself, not a curriculum and should not be seen as such. We have included instructional supports and strategies as a component of the model to provide educators concrete ways to implement the model. The model provides a process that teachers can use and adapt to their own professional preferences and instructional strengths. There are a wide array of instructional activities that could be implemented within the context of the model and teachers could develop curricular materials to support their implementation of the model. Our suggestions with relation to instructional strategies are just that, suggestions.

Additionally, we do not assume that students have to have specific prerequisites, cognitive or otherwise, to receive instruction using the model. Students who are already more accomplished with problem-solving, decision making, and so forth will be able to more independently use the model. However, even students whose life experiences have been very limited and who have limited capacity around problem-solving, goal-setting, and so forth will benefit from instruction using the model because they will be exposed to these key activities and, through repeated use of the model, should become better able to do these activities.
The success of the model, like other models, is dependent upon the person implementing it. One important aspect of implementing The Self-Determined Learning Model of Instruction is the process of working with students to make the questions more understandable to them, and to create a sense of ownership over those questions. Teachers implementing the model will use a variety of skills: teaching and instructional skills, facilitation skills, and advocacy skills. In a sense, the model provides a structure for educators to hone their skills in supporting student-directed learning, as much as it provides a means of teaching students. This is, however, an outcome that many teachers believe is important. It is, not coincidentally, also something that most state and local schools believe is important. State and local performance standards often include multiple standards and performance goals related to students exhibiting problem-solving, decision-making, and goal-setting skills as well as focusing on students' communicating their interests and preferences and articulating the match between their strengths and particular domains, such as employment. The model was designed for all students, and can be implemented as a means to enhance student access to the general curriculum and to promote inclusion.

\section{REFERENCES}

Agran, M. (1997). Student-directed learning: Teaching self-determination skills. Pacific Grove, CA: Brooks/Cole.*

Agran, M., Blanchard, C., \& Wehmeyer, M. (in press). Enhancing outcomes via The Self-Determined Learning Model of Instruction. Education and Training in Mental Retardation and Developmental Disabilites.

Agran, M., \& Martin, J. E. (1987). Applying a technology of selfcontrol in community environments for individuals who are mentally retarded. In M. Hersen, R. M. Eisler, and P. M. Miller (Eds.), Progress in behavior modification (pp. 108-151). Newbury Park, CA: Sage.*

Agran, M., \& Wehmeyer, M. L. (1999). Teaching problem solving to students with mental retardation. Washington, DC: American Association on Mental Retardation.* 
Bandura, A. (1986). Social foundations of thought and action: A social cognitive theory. Englewood Cliffs, NJ: Prentice Hall.*

Cardillo, J. E. (1994). Summary score conversion key. In T. J. Kiresuk, A. Smith, and J. E. Cardillo (Eds.). Goal attainment scaling: Applications, theory and measurement (pp. 273-281). Hillsdale, NJ: Laurence Elbaum.

Carr, R. W (1979). Goal attainment scaling as a useful tool for evaluating progress in special education. Exceptional Children, 46, 88-95.

Field, S., Martin, J., Miller, R., Ward, M., \& Wehmeyer, $M$. (1998). A practical guide to teaching self-determination. Reston, VA: The Council for Exceptional Children.

Joyce, B., \& Weil, M. (1980). Models of teaching (2nd ed.). Englewood Cliffs, NJ: Prentice Hall.*

Kanfer, F. H., \& Goldstein, A. P. (1986). Helping people change: A textbook of methods (3rd ed.). New York: Pergamon Press.*

Kiresuk, T. J., Smith, A., \& Cardillo, J. E. (1994). Goal attainment scaling: Applications, theory and measurement. Hillsdale, NJ: Lawrence Erlbaum.*

Martin, J. E., Burger, D. L., Elias-Burger, S., \& Mithaug, D. E. (1988). Applications of self-control strategies to facilitate independence in vocational and instructional settings. In N. Bray (Ed.), International review of research in mental retardation (pp. 155193). San Diego, CA: Academic Press.*

Martin, J. E., \& Marshall, L. H. (1996). ChoiceMaker: Infusing self-determination instruction into the IEP and transition process. In D. J. Sands \& M. L. Wehmeyer (Eds.), Self-determination across the life span: Independence and choice for people with disabilities (pp. 215-236). Baltimore: Paul H. Brookes.*

Martin, J. E., \& Marshall, L. H. (1998). ChoiceMaker: Choosing, planning and taking action. In M. L. Wehmeyer \& D. J. Sands (Eds.), Making it happen: Student involvement in education planning decision making and instruction (pp. 211-240). Baltimore: Paul H. Brookes.*

Mithaug, D. E., (1996a). Equal opportunity theory. Thousand Oaks, CA: Sage.*

Mithaug, D. E. (1996b). The optimal prospects principle. In D. J. Sands \& M. L. Wehmeyer (Eds.), Selfdetermination across the life span: Independence and choice for people with disabilities (pp. 147-165). Baltimore: Paul H. Brookes.*

Mithaug, D. E. (1998). Your right, my obligation? Journal of the Association for Persons with Severe Disabilities, 23,41-43.
Mithaug, D. E., Martin, J. E., \& Agran, M. (1987). Adaptability instruction: The goal of transitional programming. Exceptional Children, 53, 500-505

Mithaug, D. E., Martin, J. E., Agran, M., \& Rusch, E R. (1988). Why special education graduates fail: How to teach them to succeed. Colorado Springs, CO: Ascent.*

Mithaug, D., Wehmeyer, M. L., Agran, M., Martin, J., \& Palmer, S., (1998). The self-determined learning model of instruction: Engaging students to solve their learning problems. In M. L. Wehmeyer \& D. J. Sands (Eds.), Making it happen: Student involvement in educational planning, decision-making and instruction (pp. 299328). Baltimore: Paul H. Brookes.*

Nowicki, S., \& Duke, M. P. (1974). A locus of control scale for non-college as well as college adults. Journal of Personality Assessment, 38, 136-137.

Palmer, S., \& Wehmeyer, M. L. (1998). A teacher's guide to the use of The Self-Determined Learning Model of Instruction: Early elementary version. Arlington, TX: The Arc of the United States.*

Sands, D. J., Spencer, K., Gliner, J., \& Swaim, R. (1999). Structural equation modeling of student involvement in transition-related actions: The path of least resistance. Focus on Autism and Other Developmental Disabilities, 14,17-27.

Sarason, S. B. (1990). The predictable failure of educational reform. San Francisco: Jossey-Bass.*

Wehmeyer, M. L. (1993a). Perceptual and psychological factors in career decision-making of adolescents with and without cognitive disabilities. Career Development of Exceptional Individuals, 16,135-146.

Wehmeyer, M. L. (1993b). Factor structure and construct validity of a locus of control scale with individuals with mental retardation. Educational and Psychological Measurement, 53, 1055-1066.

Wehmeyer, M. L. (1994). Perceptions of self-determination and psychological empowerment of adolescents with mental retardation. Education and Training in Mental Retardation and Developmental Disability, 29, 9-21.

Wehmeyer, M. L. (1996a). Self-determination as an educationa outcome: Why is it important to children, youth and adults with disabilities? In D. J. Sands \& M. L. Wehmeyer (Eds.), Self-determination across the life span: Independence and choice for people with disabilities (pp. 15-34). Baltimore: Paul H. Brookes.*

Wehmeyer, M. L. (1996b). A self-report measure of self-determination for adolescents with cognitive disabilities. Education and Training in Mental Retardation and Developmental Disabilities, 31, 282-293 
Wehmeyer, M. L. (1997). Self-determination as an educational outcome: A definitional framework and implications for intervention. Journal of Developmental and Physical Disabilities, 9, 175209.

Wehmeyer, M. L. (1998). Self-determination and individuals with significant disabilities: Examining meanings and misinterpretations. Journal of the Association for Persons with Severe Handicaps, 23(1) $5-16$.

Wehmeyer, M. L., Agran, M., \& Hughes, C. (1998). Teaching self-determination to students with disabilities: Basic skills for successful transition. Baltimore: Paul H. Brookes.*

Wehmeyer, M. L., Agran, M., Palmer, S., Mithaug, D., \& Blanchard, C. (1998). A teacher's guide to the use of The Self-Determined Learning Model of Instruction: Adolescent version. Arlington, TX: The Arc of the United States.*

Wehmeyer, M. L., \& Kelchner, K. (1995). The Arc's self-determination scale. Arlington, TX: The Arc of the United States.*

Wehmeyer, M. L., \& Schwartz, M. (1997). Self-determination and positive adult outcomes: A follow-up study of youth with mental retardation or learning disabilities. Exceptional Children, 63, 245255 .

Wolman, J., Campeau, P., Dubois, P., Mithaug, D., \& Stolarski, V. (1994). AIR self-determination scale and user guide. Palo Alto, CA: American Institute for Research.

Zhang, D. (1998). The effect of self-determination instruction on high school students with mild disabilities. Unpublished doctoral dissertation, University of New Orleans.*

\section{ABOUT THE AUTHORS}

MICHAEL L. WEHMEYER, Research Associate Professor, Director, Self-Determination Projects; SUSAN B. PALMER, Research Assistant Professor, Project Director, Self-Determination Projects, Beach Center on Families and Disability, University of Kansas, Lawrence. MARTIN AGRAN, Professor, Department of Special Education, University of Northern Iowa, Cedar Falls. DENNIS E. MITHAUG, Professor of Education, Department of Health and Behavior Studies, Teachers College, Columbia University, New York. JAMES E. MARTIN, Professor, University of Colorado at Colorado Springs, Center for Self-Determination, Colorado.
This research was supported by U.S. Department of Education Grant \#H023C40126 awarded to The Arc. The opinions expressed herein do not necessarily reflect the position or policy of the U.S. Department of Education and no official endorsement by the Department should be inferred. The authors acknowledge the assistance of Dr. Tom Holub and Gerard Cortez in data collection activities, and extend our gratitude to the teachers in Texas and Wisconsin who participated in this research.

Please address all correspondence to Dr. Wehmeyer, 3136 Haworth Hall, University of Kansas, Lawrence, KS 66045.

Manuscript received March, 1999; manuscript accepted October, 1999.

\section{\#BOakA}

*To order books referenced in this journal, please call 24 hrs/365 days: 1 (800) BOOKSNOW (266-5766); or 1732-728-1040; or visit them on the Web at http:// www.Books-Now.com/Exceptional Children.htm. Use Visa, M/C, AMEX, Discover, or send check or money order $+\$ 4.95 \mathrm{~S} \& \mathrm{H}(\$ 2.50$ each add'1 item) to: Clicksmart, 400 Morris Avenue, Long Branch, NJ 07740; 1-732-728-1040 or FAX 1-732-7287080.

\section{INDEX OF ADVERTISERS}

AFB Press, $\mathrm{p} 470$

American Institute for Research, cover 2

Charles Thomas, p 433 The Council

for Exceptional Children, p 471, cover 4,

Fairfax County Public Schools, p 545 SAIC, p 529

Saxon Publishers, p 567

The Serena Merck Memorial Award, cover 3 